\title{
Livro didático de História: conhecimento histórico e didática da história no mundo contemporâneo
}

\author{
Prof. a. Dra. Marlene Rosa Cainelli ${ }^{1}$ \\ Prof. a. Dra. Sandra Regina Ferreira de Oliveira ${ }^{2}$
}

Neste dossiê, intitulado "Livro didático de História: conhecimento histórico e didática da História no mundo contemporâneo", reunimos artigos com discussões sobre a produção e uso do livro didático e suas políticas de avaliação. Dois eventos realizados na Universidade Estadual de Londrina contribuíram, direta ou indiretamente, com o estudo sobre o livro didático no Brasil e os resultados de tais estudos se fazem presentes nas questões apresentadas nos textos que, dentre outras temáticas, avançam quanto à compreensão do espaço que o livro didático assume na atualidade. O primeiro evento foi a participação da UEL no Programa Nacional do Livro Didático - 2017 (PNLD - 2017), no período de 2015 a 2017. O segundo deles, ocorrido em outubro de 2017, foi a realização do Seminário "Livro Didático de História: Conhecimento Histórico e Didática da História no Mundo Contemporâneo".

O debate em torno do que é um bom manual didático em História sempre esteve presente entre os segmentos da sociedade ${ }^{3}$ e são vários os processos instaurados, pelas mais diferentes pessoas e instituições, demandando do Ministério da Educação (MEC) explicações e reformulações quanto ao tratamento que os autores concedem a este ou aquele conteúdo. Em paralelo a um expressivo crescimento quanto ao conhecimento no

\footnotetext{
1 Professora do Departamento de História e Pesquisadora do Programa de Mestrado e Doutorado em Educação e do programa de Mestrado em História- Coordenadora Institucional do PNLD /2017.

2 Professora do departamento de Pedagogia da Universidade Estadual de Londrina e Pesquisadora do Programa de Mestrado e Doutorado em Educação- Coordenadora Pedagógica do PNLD/2017.

${ }^{3}$ Sobre o assunto ver MIRANDA; ALVIM. (2013) e CASSIANO (2017), dentre outros.
} 
campo da Didática da História, vivenciamos, nas últimas décadas no país, a intensificação das contestações sobre a História que se ensina na escola, interpelações estas que precisam ser compreendidas a partir de um contexto expandido, pois colocam em disputa o projeto de Educação escolar do país.

Segundo o Historiador Jörn Rüsen (2011, p. 115) o livro didático ideal teria quatro características importantes: um formato claro e estruturado; uma estrutura didática clara; uma relação produtiva com o aluno; e uma relação com a prática da sala de aula.

Ao elegermos os temas a serem contemplados na apresentação deste dossiê, optamos por explanar, com algumas minúcias, os caminhos e descaminhos vivenciados durante o processo de avaliação de obras didáticas de História articulando com o decurso da gestão pública, revisitando e transcrevendo trechos de documentos que registram o projeto de Educação em pauta.

Há tempos em que a tarefa do historiador é intensificada quanto a sua função de chamar o passado para contextualizar e ampliar a compreensão das infindáveis disputas do tempo presente. Em 1993, Jacques Le Goff, ao prefaciar a obra póstuma e inacabada de Marc Bloch, Apologia da História ou $O$ ofício de historiador, reeditada por seu filho Étienene Bloch, finaliza argumentando de que a obra é produto de um momento no qual Bloch "[...] capta os primeiros frêmitos de uma esperança, tanto de uma libertação da história, que é preciso ajudar na resistência ativa, como de um progresso da ciência histórica, que é preciso esclarecer escrevendo este livro" (2001, p. 34). Oito anos após, na apresentação para a edição brasileira, Lilia Schwarcz destaca os tempos difíceis a partir do qual Bloch escreve a obra e conclui que:

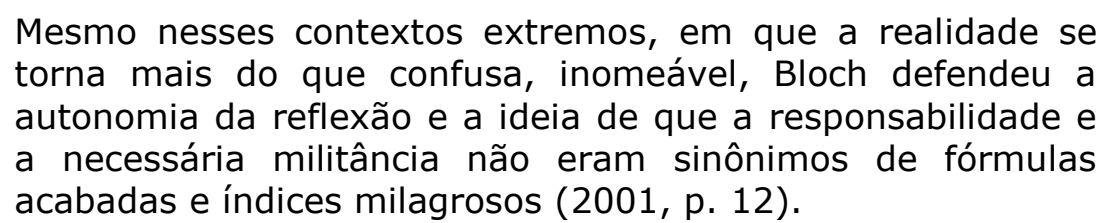

História \& Ensino, Londrina, v. 24, n.2, p.13-28, jul./dez. 2018 
Le Goff e Schwarcz formulam seus argumentos tendo por referência a reflexão inacabada de Bloch que nos coloca a pensar sobre o ofício do historiador o qual deve, a todo momento, questionar as evidências:

[...] preciso prová-la. Depois, uma vez fornecida esta prova que não temos o direito de considerar evidente, ou mesmo antecipadamente impraticável - restava ainda, aprofundando mais a análise, perguntar-se por que, de todas as atitudes psicológicas possíveis, estas se impuseram ao grupo. Pois, a partir do momento em que uma reação da inteligência ou da sensibilidade não for natural, ela exige, por sua vez, caso se produza, que nos esforcemos para descobrir suas razões. Resumindo tudo, as causas, em história como em outros domínios, não são postuladas. São buscadas. (BLOCH, 2001, p. 159).

O inacabamento do texto nos coloca frente ao convite de prosseguir com as buscas em todos os campos nos quais se fizer necessário. Hoje, no mundo contemporâneo, o campo do Ensino de História, e, em particular, no que se refere à produção de material didático para essa área do conhecimento, se configura como um campo emergencial para o historiador exercer o seu ofício.

\section{O PNLD 2017 - História: contexto e desdobramentos}

No ano de 2015, a Universidade Estadual de Londrina foi selecionada, via Chamada Pública SEB/MEC No 01/2015, para coordenar o processo de avaliação pedagógica dos livros didáticos de História destinados aos alunos e professores dos anos finais do ensino fundamental. Naquele ano, quando tomamos a decisão de participar do processo de seleção, o país vivenciava o primeiro ano do segundo mandato da Presidenta Dilma Rousseff, eleita em outubro de 2014, em pleito no qual concorreu à reeleição pela chapa liderada pelo Partidos dos Trabalhadores ${ }^{4}$ (PT), tendo por vice Michel Temer, do Partido do Movimento Democrático Brasileiro (PMDB). O então senador Aécio Neves, candidato opositor pela chapa encabeçada pelo Partido Social Democrata Brasileiro ${ }^{5}$ (PSDB) e seus aliados, questionaram,

\footnotetext{
${ }^{4}$ Coligação "Com a força do povo", PT, PMDB, PSD, PP, PR, PDT, PRB, PRÓS e PCdoB.

${ }^{5}$ Coligação "Muda Brasil", PSDB, SD, PMN, PEN, PTN, PTC, DEM, PTdoB e PTB.
} 
abertamente, o resultado das urnas e colocaram em curso um regime de oposição que, distanciando dos temas voltados para o desenvolvimento social, cultural e econômico do país, pautou-se no acirramento de um processo de construção de um inimigo nacional comum, o Partido dos Trabalhadores, na figura da então Presidenta e do ex-Presidente Luiz Inácio Lula da Silva, que governou o país de 2003 à 2010.

Problemas crônicos do sistema político brasileiro, cuja origem pode ser identificada em nosso passado colonial, patriarcal e escravocrata, foram simplificados e personificados vendendo-se a ideia de que extirpando tais pessoas, ou partidos, os problemas nacionais seriam resolvidos. No que se relaciona ao objeto desse dossiê, consideramos importante destacar que o cenário político nacional, em curso durante a realização do PNLD/2017 (que para as universidades respondentes à Chamada Pública realizada pelo MEC, teve início em 2015 e finalização em $2017^{6}$ ), precisa ser registrado, pois influenciou, efetivamente, na redefinição dos contornos ao qual foi submetido o programa após o golpe de 2016 que levou à presidência de Michel Temer (PMDB).

No Ministério da Educação, o entra e sai de mandatários seguiu o clima conturbado vivenciado no país nos anos de 2015 e 2016: Cid Gomes (PDT) assume o ministério em 02 de janeiro de 2015 e permanece por menos de três meses, deixando a pasta em 19 de março. Em abril de 2015, o professor de Ética e Filosofia Política da Universidade de São Paulo, Renato Janine Ribeiro, assume o cargo, permanecendo no mesmo até outubro do mesmo ano quando, em meio à readequação política no governo, é substituído por Aloizio Mercadante (PT) que ficará no cargo até 11 de maio de 2016, dias antes do início da tramitação do processo de afastamento da Presidenta Dilma, finalizado em 31 de agosto de 2016. Em seu lugar, Michel Temer indica Mendonça Filho (DEM), que sairá em abril de 2018 para concorrer a uma vaga no senado pelo estado de Pernambuco, não sendo eleito.

${ }^{6} \mathrm{O}$ prazo de finalização do PNLD em cada universidade pode apresentar variações ditadas pelas demandas dos editais e recursos. 
Na Secretaria de Educação Básica (SEB) e na Coordenação de Materiais Didáticos (COGEAM) - setores diretamente responsáveis pela implementação das políticas públicas sobre o livro didático no Ministério da Educação - a alteração nos cargos de chefia foi menor, o que, de certa forma, favoreceu à realização do PNLD 2017 em patamares menos conflituosos quanto à relação da Universidade com o Governo Federal. A Secretaria de Educação Básica (SEB) passou pela coordenação de Maria Beatriz Luce, pedagoga e professora da Universidade Federal do Rio Grande do Sul (UFRGS) e Rossiele Soares da Silva, advogado e ex-Secretário de Educação do Estado do Amazonas. Na COGEAM, passaram pela coordenação Junia Salles Moreira, historiadora e professora da Universidade Federal de Minas Gerais (UFMG) e Tassiana Cunha Carvalho, Cientista Política e funcionária de carreira do MEC. Durante alguns meses, Cristina Thomas de Ross, funcionária de carreira do MEC, respondeu pela COGEAM até a efetivação da Tassiana Cunha Carvalho no quadro.

A realização de cada etapa do PNLD é marcada por uma exaustiva rotina de reuniões, envolvendo os responsáveis pelas pastas, os coordenadores do processo avaliativo e os representantes das editoras. Os gestores são peças fundamentais nesse processo e a depender de seu entendimento, envolvimento e atuação no campo da Educação escolar, e, em especial, no campo da produção de material didáticos, vai se constituindo um perfil para o que se entende por um bom livro didático que pode, ou não, influenciar na elaboração dos mesmos, considerando que estamos a tratar de processos com uma temporalidade alargada. Por isso, entendemos que o estudo minucioso do histórico de cada processo avaliativo, em suas singularidades e abrangendo vários escalões do MEC, forneceria dados importantes para a compreensão de como vai se configurando, e também se desconfigurando, os desenhos de uma política pública para a elaboração, avaliação e distribuição dos livros didáticos no país.

Retornando ao PNLD - 2017 - História, sob a responsabilidade da UEL, o resultado da Chamada Pública SEB/MEC No 01/2015 foi publicado via 
Portaria no 28, de 10 de Agosto de 2015, e divulgado no Diário Oficial da União do dia 11 de Agosto de 2015 (Figura 1). Foram selecionadas sete instituições, sendo a UEL a única instituição estadual. Não temos conhecimento do número de concorrentes em cada componente curricular e esta informação seria relevante, pois indicaria o interesse e envolvimento das universidades públicas com o processo de avaliação dos livros didáticos.

Figura 1: Instituições públicas selecionadas para coordenação do PNLD 2017

\begin{tabular}{|l|l|}
\hline Componente Curricular & Instituição Pública Selecionada \\
\hline Arte & $\begin{array}{l}\text { Universidade Federal do Rio Grande do } \\
\text { Sul - UFRGS }\end{array}$ \\
\hline Ciências & $\begin{array}{l}\text { Universidade Federal do Triângulo } \\
\text { Mineiro - UFTM }\end{array}$ \\
\hline Geografia & $\begin{array}{l}\text { Universidade Federal do Rio Grande do } \\
\text { Sul - UFRG }\end{array}$ \\
\hline História & $\begin{array}{l}\text { Universidade Estadual de Londrina - } \\
\text { UEL }\end{array}$ \\
\hline Língua Estrangeira Moderna & Universidade Federal da Bahia - UFBA \\
\hline Língua Portuguesa & $\begin{array}{l}\text { Universidade Federal de Pernambuco - } \\
\text { UFPE }\end{array}$ \\
\hline Matemática & $\begin{array}{l}\text { Universidade Federal de Pernambuco - } \\
\text { UFPE }\end{array}$ \\
\hline
\end{tabular}

Fonte: Diário Oficial da União do dia 11 de agosto de 2015

Em dezembro de 2015, publica-se no Diário Oficial da União a Resolução no 13, de 4 de Dezembro de 2015, na qual o Presidente Substituto do Conselho Deliberativo do Fundo Nacional de Desenvolvimento da Educação - FNDE aprova o apoio financeiro para a UEL realizar o PNLD 2017- História. O que se seguiu foi um amplo processo de adequações e gerenciamentos entre a Secretaria de Educação Básica, por meio da Coordenação Geral de Material Didático, então sob a coordenação de Tassiana Cunha Carvalho $^{7}$, visto que, como já dito, a UEL foi a única instituição estadual selecionada, o que demandou ajustes no sistema de descentralização de verbas por se tratar de transferência de recursos entre

7 O processo de avaliação das obras teve início no mês de dezembro de 2015, antes da liberação dos recursos, devido a mediação da COGEAM que custeou as passagens e a estadia dos avaliadores para a realização do primeiro treinamento. 
esferas administrativas distintas (federal e estadual). Efetivamente, os recursos chegaram à UEL no mês de março de 2016. Apresentamos tais dados para registrar e fomentar futuros estudos sobre o tratamento que as políticas públicas sobre o livro didático receberam do governo federal ao longo de quase um século de existência, a considerar como marco inicial a criação do Instituto Nacional do Livro (INL), em 1929. Em 1994, no governo de Fernando Henrique Cardoso (PSDB), coloca-se, em curso, um processo de retomada e redefinições quanto à distribuição e avaliação dos livros, o qual confere os contornos ao PNLD, vigorando, com alterações, até os dias atuais.

O MEC nomeou para a coordenação técnica do PNLD 2017, cuja função foi estabelecer o contato entre o MEC e a Instituição que sediaria o processo de avaliação, a Profa Dra Ana Maria Ferreira da Costa Monteiro, da Universidade Federal do Rio de Janeiro (UFRJ), e o nome de todos os participantes do processo está publicado junto ao Guia PNLD 2017 História, disponível na página do Fundo Nacional de Desenvolvimento da Educação (FNDE) ${ }^{8}$ (BRASIL, 2016).

Nos textos de introdução do Guia citado ${ }^{9}$, para além da contextualização de todo processo, da apresentação dos dados e das análises do Edital PNLD 2017, tem-se um estudo que detalha como as coleções aprovadas abordam os seguintes eixos: tratamento escolar das fontes históricas; relação entre texto-base e atividades; tratamento da temporalidade histórica; Temática Africana e Temática Indígena.

Cada um dos eixos citados fornece uma chave de leitura para interpretar as obras aprovadas, bem como remetem a pontos cruciais que um "bom livro didático de História deveria contemplar", de acordo com o processo avaliativo e o edital que direcionou a forma e o método de avaliação. Na linha interpretativa seguida para a apresentação dos resultados no Guia optou-se por trabalhar com quatro indicadores de

${ }^{8}$ Disponível em: http://www.fnde.gov.br/programas/programas-do-livro/livro-didatico/guiado-livro-didatico/item/8813-guia-pnld-2017

9 Os textos de introdução do Guia PNLD 2017 - História foram elaborados pela Profa. Dra. Sonia Regina Miranda, da Universidade Federal de Juiz de Fora, convidada para compor a equipe na função de Coordenadora Pedagógica do Guia do Livro Didático 
qualificação, independentes entre si, e entre os quatro volumes que compõem a coleção, mas que apontam para os patamares quanto ao que se espera com relação à progressão da complexidade em torno do tratamento do eixo, ao longo da coleção. Além disso, se o professor colocar lado a lado os resultados de cada coleção, disponibilizada no Guia em formato de alvos, o documento oferece dados que permitem compreender as diferenças entre as coleções. Os indicadores de qualificação dos eixos (Figura 2) foram formulados a partir do exigido no Edital PNLD 2017 - História, em seu Anexo III.

Figura 2 - Eixos e indicadores de qualificação (IQ) - PNLD 2017 História

\begin{tabular}{|c|c|c|c|c|c|}
\hline$\stackrel{\circ}{\stackrel{\circ}{x}}$ & $\begin{array}{l}\text { Tratamento } \\
\text { escolar das } \\
\text { fontes } \\
\text { históricas }\end{array}$ & $\begin{array}{l}\text { Relação } \\
\text { entre texto- } \\
\text { base e } \\
\text { atividades }\end{array}$ & $\begin{array}{l}\text { Tratamento da } \\
\text { temporalidade } \\
\text { histórica }\end{array}$ & $\begin{array}{l}\text { Temática } \\
\text { Africana }\end{array}$ & $\begin{array}{l}\text { Temática } \\
\text { Indígena. }\end{array}$ \\
\hline$\stackrel{+}{\sigma}$ & $\begin{array}{l}\text { A função } \\
\text { ilustrativa e } \\
\text { favorecedora } \\
\text { do acesso } \\
\text { ao conteúdo } \\
\text { dos livros } \\
\text { por parte do } \\
\text { jovem }\end{array}$ & $\begin{array}{l}\text { Relação entre } \\
\text { textos-base e } \\
\text { atividades }\end{array}$ & $\begin{array}{ll}\text { Apresenta } & \\
\text { orientações } & \\
\text { acerca } & \text { de } \\
\text { operações } & \text { de } \\
\text { datação } & \end{array}$ & $\begin{array}{l}\text { Inscrição } \\
\text { informativa } \\
\text { e } \\
\text { cronológica }\end{array}$ & $\begin{array}{l}\text { Inscrição } \\
\text { informativa } \\
\text { e } \\
\text { cronológica }\end{array}$ \\
\hline$\underset{n}{N}$ & $\begin{array}{l}\text { A diversidade } \\
\text { de gêneros } \\
\text { textuais } \\
\text { disponíveis } \\
\text { para o } \\
\text { trabalho } \\
\text { didático; }\end{array}$ & $\begin{array}{l}\text { Propõe } \\
\text { possibilidades } \\
\text { de } \\
\text { relacionament } \\
\text { o entre } \\
\text { passado e } \\
\text { presente }\end{array}$ & $\begin{array}{l}\text { Contempla o } \\
\text { tratamento da } \\
\text { simultaneidade } \\
\text { histórica }\end{array}$ & $\begin{array}{l}\text { Densidade } \\
\text { na } \\
\text { orientação } \\
\text { teórico- } \\
\text { metodológic } \\
\text { a para } \\
\text { professor }\end{array}$ & $\begin{array}{l}\text { Densidade } \\
\text { na } \\
\text { orientação } \\
\text { teórico- } \\
\text { metodológic } \\
\text { a para } \\
\text { professor }\end{array}$ \\
\hline$\stackrel{m}{\stackrel{m}{H}}$ & $\begin{array}{l}\text { A natureza e } \\
\text { a densidade } \\
\text { da } \\
\text { orientação } \\
\text { metodológica } \\
\text { ao docente; }\end{array}$ & $\begin{array}{l}\text { Favorece o } \\
\text { trabalho em } \\
\text { coletivo na } \\
\text { sala de aula }\end{array}$ & $\begin{array}{l}\text { Favorece uma } \\
\text { comparação } \\
\text { problematizador } \\
\text { a entre passado } \\
\text { e presente }\end{array}$ & $\begin{array}{l}\text { Visibilidade } \\
\text { ao } \\
\text { protagonism } \\
\text { o dos } \\
\text { sujeitos ao } \\
\text { longo do } \\
\text { tempo }\end{array}$ & $\begin{array}{l}\text { Visibilidade } \\
\text { ao } \\
\text { protagonism } \\
\text { o dos } \\
\text { sujeitos ao } \\
\text { longo do } \\
\text { tempo }\end{array}$ \\
\hline
\end{tabular}




\begin{tabular}{|c|c|c|c|c|c|}
\hline $\begin{array}{l}\stackrel{+}{\sigma} \\
\underset{H}{\sigma}\end{array}$ & $\begin{array}{l}\text { O } \\
\text { favoreciment } \\
\text { o da } \\
\text { compreensão } \\
\text { do } \\
\text { procediment } \\
\text { o } \\
\text { histórico, por } \\
\text { meio de } \\
\text { orientações } \\
\text { metodológica } \\
\text { s precisas ao } \\
\text { estudante. }\end{array}$ & $\begin{array}{l}\text { Estimula } \\
\text { habilidade de } \\
\text { pensamento } \\
\text { de } \\
\text { complexidade } \\
\text { variada. }\end{array}$ & $\begin{array}{l}\text { Possibilita a } \\
\text { construção da } \\
\text { noção de } \\
\text { duração }\end{array}$ & $\begin{array}{l}\text { Promoção } \\
\text { da educação } \\
\text { para as } \\
\text { relações } \\
\text { étnico- } \\
\text { raciais. }\end{array}$ & $\begin{array}{l}\text { Promoção } \\
\text { da educação } \\
\text { para as } \\
\text { relações } \\
\text { étnico- } \\
\text { raciais. }\end{array}$ \\
\hline
\end{tabular}

Fonte: Adaptado pelas autoras do Guia do PNLD 2017 - História. (BRASIL, 2016, p. $26-35$ )

Os cinco eixos e os quatro indicadores de qualificação, acrescidos da análise, também apresentada no Guia, quanto à concepção sobre os significados de ensinar e aprender História para jovens no ensino fundamental, que alicerçava o Edital 2017, balizaria o perfil de livro didático de História almejado e indicaria os desafios a serem enfrentados. Dentre tantos desafios destacamos:

[...] a proposição de um ensino que conecte, efetivamente, os jovens a um saber contextualizado e que promova o protagonismo juvenil, dimensão tão cara, em nosso caso, à construção da compreensão da noção de sujeito histórico. (GUIA PNLD 2017, p. 10).

Chegamos, assim, ao segundo evento que confere contornos a proposição deste dossiê: a realização, em outubro de 2017, do Seminário "Livro Didático de História: Conhecimento Histórico e Didática da História no Mundo Contemporâneo". A realização de uma ação avaliativa no formato evento, foi uma das propostas constantes no plano de trabalho enviado, quando da participação da Chamada Pública SEB/MEC No 01/2015. A princípio, e em síntese, seu objetivo seria avançar na construção de caminhos para os desafios identificados durante o processo de avaliação. No entanto, o sistema público de Educação no país, nos anos de 2016 e 2017, foi assolado por uma série de acontecimentos que imprimiram urgências quanto à discussão sobre o que se entende por conhecimento histórico, bem como a respeito de qual seu lugar e função na escola. 
O acirramento de posições em torno do processo de elaboração da Base Nacional Comum Curricular (BNCC) e as alterações impetradas no PNLD via decreto, redimensionaram o formato e a dimensão do Seminário, cujo objetivo inicial era promover análises que nos auxiliassem a compreender a relação entre a historiografia e os conteúdos nos livros didáticos de História, na almejada articulação com o pensamento dos jovens e as narrativas do mundo contemporâneo, fosse ampliado a fim de contemplar temáticas que contribuíssem com o pensar de caminhos para o livro de História, seja no contexto das reformulações em curso no PNLD, seja quanto às perspectivas para o mesmo na relação com a BNCC.

\section{O livro didático e sua função em meio aos embates contemporâneos}

Considerando o que estamos vivenciando no país nos últimos quatros anos (2015 - 2018), observamos que os textos presentes neste dossiê transitam por temáticas que reafirmam, e aprofundam, princípios do Ensino de História (muitos dos quais anunciados no já citado Guia PNLD 2017 História) construídos ao longo de décadas, em diferentes países do mundo, por pessoas que tem o campo do Ensino de História como lugar de ofício, quer seja na pesquisa, docência ou mesmo na produção de material didático. O resultado de todo esse trabalho foi (e continua sendo) publicado em diversos livros, periódicos, eventos e encontros. Portanto, estamos a tratar de uma caminhada construída passo a passo, pesquisa a pesquisa, aula a aula, ao longo de 30 anos, a qual fornece respostas plausíveis para o que se compreende por conhecimento histórico e em como ensiná-lo na escola. Estamos a tratar da Didática da História e de um dos temas caros a esse campo - o livro didático. Nesse sentido, não podemos silenciar frente a propostas que, simplesmente, desconsiderem toda a produção científica de uma área. 
Ao longo do século $X X$, o livro da História da humanidade ampliou-se com capítulos dolorosos e sangrentos, mas, também, com conquistas científicas que redimensionaram as relações entre as pessoas em todo o planeta. Recorrer a Marc Bloch para iniciar a apresentação deste dossiê tem toda uma simbologia e direciona nosso objetivo para muitos comprometimentos. No Brasil, avançamos na produção de uma historiografia que valorizou outros eixos, para além do político, e possibilitou conhecer as várias histórias que formam a História do Brasil. Nos documentos curriculares produzidos no final da década de 1980, no contexto de redemocratização nacional, já se identifica o questionamento a um ensino de História direcionado somente para o passado e pautado na memorização de alguns fatos canônicos de uma história erigida a versão oficial (BITTENCOURT, 1998)

No apagar das luzes do século XX, a promulgação da Lei de Diretrizes e Bases (LDB 9394/1996) reafirma e legaliza, em seu artigo terceiro, o compromisso do país em construir um sistema de Educação Escolar baseado nos seguintes princípios:

I - Igualdade de condições para o acesso e permanência na escola. II - Liberdade de aprender, ensinar, pesquisar e divulgar a cultura, o pensamento, a arte e o saber. III Pluralismo de ideias e de concepções pedagógicas. IV Respeito à liberdade e apreço à tolerância. V - Coexistência de instituições públicas e privadas de ensino. VI - Gratuidade do ensino público em estabelecimentos oficiais. VII valorização do profissional da educação escolar. VIII - gestão democrática do ensino público, na forma desta Lei e da legislação dos sistemas de ensino. IX - Garantia de padrão de qualidade. $X$ - Valorização da experiência extraescolar. XI - Vinculação entre a educação escolar, o trabalho e as práticas sociais. XII - Consideração com a diversidade étnico-racial. (BRASIL, 1996)

O contexto de elaboração e promulgação da LDB foi marcado por divergências, mas não identificamos, até o fechamento deste texto, estudos que apontem rupturas quanto a indicação de tais princípios como estruturantes da Educação Escolar no país. Podemos concluir que, em 1996, havia um certo consenso em torno de tais princípios. É neste contexto que são publicados os Parâmetros Curriculares Nacionais, em 1997 (BRASIL, 
1997), com o objetivo de indicar, como o nome mesmo assinala, parâmetros para a elaboração das propostas curriculares dos estados e municípios. Em sintonia com o preconizado na Lei, e como uma tentativa de concretizar nas escolas os princípios anunciados, O MEC elege os temas Ética, Saúde, Meio Ambiente, Orientação Sexual, Trabalho e Consumo, e Pluralidade Cultural, para que perpassem todas as disciplinas e os anos de escolaridade, denominando-os por Temas Transversais.

Nas primeiras décadas do século XXI, fomentou-se a necessidade de olhar ao redor e identificar as diferenças, de todos os tipos, para podermos construir relações de respeito, de empatia. No campo específico da História, os estudos sobre nosso passado, a partir dos mais variados recortes e fontes, e sob a liberdade de um regime democrático, ampliaram-se significativamente. Com a ampliação de universidades por todo território nacional, novos cursos de História foram criados e, em decorrência, ramificaram-se os olhares atentos para a realidade vivida, interpretando-a na constante relação temporal que caracteriza o trabalho do historiador. Soma-se, aqui, também, a ação de diversos Movimentos Sociais que, em torno de pautas distintas, colocaram em visibilidade uma cartela de justas reivindicações de populações que eram (e são) empurradas para a margem da sociedade. A conquista de direitos, por esses grupos, redimensionou, dentre outras tantas questões, o que se ensina sobre a História do Brasil na escola.

O que o livro didático de História ainda não alcançou é a capacidade de permitir ao aluno, a partir de sua leitura, chegar aos sentidos, despertar a fascinação e os raciocínios históricos. A forma de apresentação do passado nas narrativas do livro didático de História não incita a percepção das experiências históricas. Segundo Rüsen (2001, p.119) "[...] o livro didático de história deveria abrir os olhos das crianças e jovens para as diferenças históricas e as diferentes qualidades da vida humana através dos tempos." Não apresentando como fazem hoje os livros didáticos "[...] unicamente experiências históricas já interpretadas e a percepções já assimiladas de 
forma cognitiva" (p.119). Caramez (2014), em estudo com professores de História, ao analisar as relações com a experiência de utilização do livro didático, percebeu que ele não proporciona determinados tipos de experiências didáticas como, por exemplo, o uso da internet possibilitaria:

Como a ruptura com a linearidade da história, a possibilidade de visitar vários passados e de encontrar diferentes perspectivas de um mesmo acontecimento histórico, uma vez que nos livros didáticos, as fontes primárias e secundárias, geralmente, concordam com o texto didático do autor, como também, no que diz respeito à mudança na relação entre o presente e o passado, na medida em que a relação com o passado é quantitativamente aumentada e qualitativamente expandida (CARAMEZ, 2014, p. 98-99).

O livro didático de História que temos hoje no país traz em sua constituição todo esse histórico de alterações. No processo de elaboração de cada edital, a equipe técnica responsável tinha a difícil tarefa de transformar os princípios, acima elencados, em regras claras para comporem, juntamente com os saberes de cada disciplina, um conteúdo escolar. Como o PNLD é um programa de temporalidade alargada é possível, ao longo dos últimos 20 anos, identificar como os livros didáticos de História se alteraram e, sem nenhuma dúvida a respeito, se modificaram na direção de uma abordagem da História mais próxima daquela compreendida como capaz, se não de fomentar o desenvolvimento do pensamento histórico, pelo menos de permitir que os alunos tivessem acesso a uma história plural e com contornos sociais definidos por políticas públicas que inseriram, no campo da produção didática, temas antes relegados à iniciativa do professor para serem abordados em sala de aula. Como exemplo tem-se a História da África e dos africanos antes da escravização no Brasil, assim como a abordagem da História indígena antes da chegada dos portugueses por estas terras, bem como a continuidade da existência de indígenas para além do mundo colonial brasileiro. Além deles, há outros temas, já abordados pela historiografia contemporânea, mas que demoraram para serem trabalhados nos livros didáticos de História, como a História das mulheres, dos idosos ou mesmo das crianças. 
Os critérios de avaliação dos livros didáticos de História preservaram, até o momento, aquilo que é mais importante na área de História: o respeito pela produção científica. Temos de garantir que sejam quais forem os princípios e critérios propostos para avaliação de livros didáticos, estes estejam representados pela pluralidade de ideias, bem como pelo rigor metodológico e científico e, de igual modo, que a legitimidade dos conteúdos históricos seja determinada pela ciência histórica e não por valores morais ou religiosos. Pensando, como afirma Isabel Barca, que a avaliação de livros didáticos se insere em políticas públicas para formação de cidadãos, defendemos que estes sejam avaliados com o objetivo de formar gente livre, com ideias próprias e atentas ao que se passa à sua volta, em vez de simples cidadãos - robôs, muito competentes tecnicamente, mas que não pensam por suas consciências, e sim, o que Ihes propõem pensar. Estes objetivos são importantes para defesa dos valores da democracia e da liberdade em sociedades contemporâneas.

\section{Referências}

BITTENCOURT, Circe Maria Fernandes. Propostas curriculares de História: continuidades e transformações. In: BARRETO, Elba S. de Sá. (Org.). Os currículos no ensino fundamental para as escolas brasileiras. São Paulo: Autores Associados/Fundação Carlos Chagas, 1998, p. 127-161.

BLOCH, Marc. Apologia da história ou O ofício de historiador. Rio de Janeiro: Jorge Zahar, 2001.

BRASIL, Lei de Diretrizes e B. Lei no 9.394/96, de 20 de dezembro de 1996.

BRASIL, Ministério da Educação e do Desporto, Secretaria de Educação Fundamental. Parâmetros curriculares nacionais. Brasília: MEC/SEF, 1997.

BRASIL, Ministério da Educação e do Desporto, Secretaria de Educação Fundamental. Parâmetros curriculares nacionais - História/Geografia (1 ${ }^{a}$ a 4a séries). Brasília: MEC/SEF, 1997. 
BRASIL, Ministério da Educação e do Desporto, Secretaria de Educação Fundamental. Parâmetros curriculares nacionais - História. Brasília: MEC/SEF, 1998.

BRASIL. Guia dos livros didáticos. PNLD 2017: História - Ensino Fundamental/anos finais. Brasília, DF: Mistério da Educação, Secretaria de Educação Básica, Fundo Nacional de Desenvolvimento da Educação, 2016.

BRASIL. Ministério da Educação. Secretaria da Educação Fundamental. Edital de Convocação 02/2015 - CGPLI: Edital PNLD/2017.

CARAMEZ, Cláudia Senra. A aprendizagem histórica de professores mediada pelas tecnologias da informação e comunicação: perspectivas da educação histórica. 2014. Dissertação (Mestrado em Educação) - Setor de Educação da Universidade Federal do Paraná, Curitiba.

CASSIANO, Célia Cristina de Figueiredo. Política e economia do mercado do livro didático no século XXI: globalização, tecnologia e capitalismo na educação básica nacional. In: ROCHA, Helenice; REZNIK, Luis; MAGALHÃES, Marcelo de Souza (Org.). Livros didáticos de história: entre políticas e narrativas. Rio de Janeiro: FGV Editora, 2017, p. 83 - 100.

LE GOFF, Jacques. Prefácio, por Jacques Le Goff. In: BLOCH, Marc. Apologia da história ou O ofício de historiador. Rio de Janeiro: Jorge Zahar, 2001, p. $15-34$.

MIRANDA, Sonia Regina; ALVIM, Yara. Livros na batalha de ideias: a sedução da verdade no debate público em torno dos livros didáticos de história. In: GALZERANI, Maria Carolina Bovèrio; PINTO JUNIOR, Arnaldo; BUENO, João Batista Gonçalves (Org.). Paisagens da Pesquisa Contemporânea sobre o Livro Didático de História. Campinas: Paco Editorial/ Centro Memória Unicamp, 2013, p. 373-398.

RÜSEN, Jörn. O livro didático ideal. In Schmidt, M.A., Barca, I., \& Martins, E.R.. Jörn Rüsen e o ensino de história. Curitiba: Editora da UFPR; Braga (PT): Uminho. 2010

SCHWARCZ, Lilian Moritz. Apresentação à edição brasileira. In: BLOCH, Marc. Apologia da história ou O ofício de historiador. Rio de Janeiro: Jorge Zahar, 2001, p. 7 - 12. 